\title{
Processes and technologies for the recycling of spent fluorescent lamps
}

\author{
Wojciech Kujawski ${ }^{1 *}$, Beata Pospiech ${ }^{2 *}$ \\ ${ }^{1}$ Faculty of Chemistry Nicolaus Copernicus University, ul. Gagarina 7, 87-100 Torun, Poland \\ ${ }^{2}$ Czestochowa University of Technology, Department of Chemistry, ul. Armii Krajowej 19, 42-200 Czestochowa, Poland \\ "Corresponding authors: e-mail: wojciech.kujawski@chem.umk.pl, b.pospiech@wip.pcz.pl
}

\begin{abstract}
The growing industrial application of rare earth metals led to great interest in the new technologies for the recycling and recovery of REEs from diverse sources. This work reviews the various methods for the recycling of spent fluorescent lamps. The spent fluorescent lamps are potential source of important rare earth elements (REEs) such as: yttrium, terbium, europium, lanthanum and cerium. The characteristics of REEs properties and construction of typical fluorescent lamps is described. The work compares also current technologies which can be utilized for an efficient recovery of REEs from phosphors powders coming from spent fluorescent lamps. The work is especially focused on the hydrometallurgical and pyrometallurgical processes. It was concluded that hydrometallurgical processes are especially useful for the recovery of REEs from spent fluorescent lamps. Moreover, the methods used for recycling of REEs are identical or very similar to those utilized for the raw ores processing.
\end{abstract}

Keywords: fluorescent lamps, recycling, rare earth elements, hydrometallurgical process, pyrometallurgical process, solvent extraction, leaching.

\section{INTRODUCTION}

One of the most important applications of rare earth metals (REEs) is the production of luminescent materials (phosphors) which are used as components of the fluorescent lamps. There are two types of lamps that are commonly used nowadays: lamps containing mercury (so called fluorescent lamps) and lamps without mercury (incandescent lamps and halogen/dichroic lamps) ${ }^{1}$. There are various kinds of commercial light sources containing mercury, including cathode fluorescent lamps (CCFLs), ultraviolet (UV) lamps and high pressure mercury lamps (SHPs). The CCFLs are components of liquid crystal display tv-sets (LCD TV), LCD monitors and scanners². All fluorescent lamps contain mercury, which is one of the most toxic elements and therefore belongs to hazardous substances. Development of recycling was driven by environmental and economical benefits. The European Union, under Directive 2002/95/EC on the restriction of the use of certain hazardous substances in electrical and electronic equipment (EEE) prohibited the use of these substances in electrical and electronic equipment. In case of compact fluorescent lamps (CFLs) concentration of mercury should not exceed $5 \mathrm{mg}$ per lamp. The management of spent CFLs is regulated by Directive 2002/96/EC on electrical and electronic equipment, and waste management (WEEE) [3,4]. The spent fluorescent lamps can be treated by means of mechanical, thermal and chemical processes. Several technologies for the recycling of lamp waste have been proposed ${ }^{5-11}$.

This paper reviews hydrometallurgical and pyrometallurgical technologies applied for the efficient recovery of REEs from phosphors powders. In the first part of review, the characteristic and application of REEs as well as structure of typical fluorescent lamps is discussed. In the second part, the overview of studies concerning of REEs recovery from fluorescent lamps is described.

\section{THE RARE EARTH METALS}

The rare earth metals are comprising of 14 lanthanides (cerium to lutetium), lanthanum, yttrium and scandium. The REEs are divided in two groups: the light group (the cerium group) and the heavy REEs (yttrium group). Due to their specific properties, these metals are used in various applications, like lighter flints, glass polishing, phosphors, lasers, magnets, batteries, high-temperature superconductors. The rare earth phosphors are used as the components in fluorescent lamps, having no substitutes. Europium is used in cathode-ray tubes and liquid-crystal displays, erbium - in laser repeaters for fiber-optic cables; cerium oxide is the only polishing agent for glass used in the production of mirrors, eyeglasses, and precision lenses. Neodymium, samarium, gadolinium and dysprosium are applied in the production of small, lightweight and high-strength magnets that allow miniaturization of many electrical and electronic components ${ }^{3}$. According to the recent data it can be stated that four rare earth elements (i.e. cerium, lanthanum, neodymium, and yttrium) represent almost $90 \%$ of the global production. Recycling and/or reuse of these metals is possible, but difficult. The other rare earth elements are usually utilized in much lower quantities, and for that reason the recycling would be complex and challenging, especially due to problems associated with the removal of the rare earths from the products ${ }^{\mathbf{1 2}}$.

\section{FLUORESCENT LAMPS CHARACTERISTICS}

The fluorescent lamps are gas discharge lamps which use mercury vapors to produce light ${ }^{3}$. Part of mercury introduced into a lamp is used to produce visible light and the other part of this metal interacts with the phosphor powder and the glass matrix ${ }^{4}$. The typical lamp consists of a glass tube filled with an inert gas (argon, neon, krypton and/or xenon) at low pressure (3 mbar) and mercury vapor at low partial pressure. Cathodes made of either tungsten or stainless steel are assembled on the ends of the lamp ${ }^{1}$. The inside of the tube is coated with a layer of phosphors powder. The composition of the phosphors powder is responsible for the light's color and intensity ${ }^{3}$. Rare earth elements have been widely used as luminescent materials. The characteristics of phosphor materials are shown in Table $1^{8}$. Table $2^{13}$ displays the amount of various REEs in phosphors materials. Rare 
Table 1. Characteristics of phosphor materials ${ }^{8}$

\begin{tabular}{|l|c|c|c|}
\hline Type & Simplified formula & Density $\left[\mathrm{g} \cdot \mathrm{cm}^{-3}\right]$ & Median size, $\mathrm{d}_{50}[\mu \mathrm{m}]$ \\
\hline White & $3 \mathrm{Ca}_{3}\left(\mathrm{PO}_{4}\right)_{2} \mathrm{Ca}(\mathrm{F}, \mathrm{Cl})_{2}: \mathrm{Sb}, \mathrm{Mn}$ & 3.07 & 13.42 \\
\hline Red & $(\mathrm{Y}, \mathrm{Eu})_{2} \mathrm{O}_{3}$ & 5.12 & 4.72 \\
\hline Green & $(\mathrm{La}, \mathrm{Ce}, \mathrm{Tb})(\mathrm{P}, \mathrm{B}) \mathrm{O}_{4}$ & 5.23 & 3.72 \\
\hline Blue & $(\mathrm{Sr}, \mathrm{Ca}, \mathrm{Ba}, \mathrm{Eu})_{10}\left(\mathrm{PO}_{4}\right)_{6} \mathrm{Cl} \mathrm{Cl}_{2}$ & 4.34 & 5.18 \\
\hline
\end{tabular}

Table 2. Composition of the recovered and fresh phosphors ${ }^{13}$.

\begin{tabular}{|c|c|c|c|c|c|}
\hline \multirow{2}{*}{ Component } & \multicolumn{2}{|c|}{ Content [wt\%] } & \multirow{2}{*}{ Component } & \multicolumn{2}{|c|}{ Content [wt\%] } \\
\hline & Fresh phosphors & Recovered phosphors & & Fresh phosphors & Recovered phosphors \\
\hline $\mathrm{CaO}$ & 50.9 & 49.5 & $\mathrm{Gd}_{2} \mathrm{O}_{3}$ & 0.20 & - \\
\hline $\mathrm{P}_{2} \mathrm{O}_{5}$ & 35.7 & 34.9 & $\mathrm{~Tb}_{4} \mathrm{O}_{7}$ & 0.20 & 0.16 \\
\hline $\mathrm{Y}_{2} \mathrm{O}_{3}$ & 3.28 & 3.09 & $\mathrm{Eu}_{2} \mathrm{O}_{3}$ & 0.18 & 0.19 \\
\hline $\mathrm{F}$ & 2.48 & 2.43 & $\mathrm{SiO}_{2}$ & 0.14 & 1.88 \\
\hline $\mathrm{Al}_{2} \mathrm{O}_{3}$ & 1.21 & 1.16 & $\mathrm{ZnO}$ & 0.10 & 0.02 \\
\hline $\mathrm{SrO}$ & 1.14 & 1.13 & $\mathrm{Fe}_{2} \mathrm{O}_{3}$ & 0.05 & 0.12 \\
\hline $\mathrm{Sb}_{2} \mathrm{O}_{3}$ & 1.04 & 0.91 & $\mathrm{Na}_{2} \mathrm{O}$ & 0.05 & 0.33 \\
\hline $\mathrm{MnO}$ & 0.80 & 0.82 & $\mathrm{SO}_{3}$ & 0.04 & 0.06 \\
\hline $\mathrm{La}_{2} \mathrm{O}_{3}$ & 0.79 & 0.97 & $\mathrm{HgO}$ & 0.03 & - \\
\hline $\mathrm{C}$ & 0.63 & 0.70 & $\mathrm{GeO}_{2}$ & 0.02 & 0.02 \\
\hline $\mathrm{BaO}$ & 0.54 & 0.83 & $\mathrm{PbO}$ & - & 0.23 \\
\hline $\mathrm{Cl}$ & 0.50 & 0.44 & $\mathrm{MgO}$ & 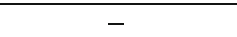 & 0.09 \\
\hline
\end{tabular}

Table 3. Chemical composition of the spent optical glass ${ }^{14}$

\begin{tabular}{|l|c|c|c|c|c|c|c|c|c|c|c|}
\hline Component & $\mathrm{La}_{2} \mathrm{O}_{3}$ & $\mathrm{Y}_{2} \mathrm{O}_{3}$ & $\mathrm{Gd}_{2} \mathrm{O}_{3}$ & $\mathrm{ZrO}_{2}$ & $\mathrm{ZnO}$ & $\mathrm{Nb}_{2} \mathrm{O}_{3}$ & $\mathrm{Sb}_{2} \mathrm{O}_{3}$ & $\mathrm{BaO}$ & $\mathrm{B}_{2} \mathrm{O}_{3}$ & $\mathrm{SiO}_{2}$ & $\mathrm{Others}$ \\
\hline Content [wt. $\%]$ & 43.1 & 9.37 & 4.60 & 6.48 & 0.25 & 3.30 & 0.13 & 1.25 & 24.5 & 6.25 & 0.77 \\
\hline
\end{tabular}

earths elements, such as lanthanum are also present in spent optical glasses. For a comparison, Table 3 presents chemical composition of the spent optical glasses ${ }^{14}$. Recently, a large number of luminescent materials based on rare earth ions or rare earth host lattices have been invented. Until 1980s, mainly halophosphate with 1-2\% antimony and manganese $\mathrm{Ca}_{5}\left(\mathrm{PO}_{4}\right)_{3}(\mathrm{~F}, \mathrm{Cl})$ :(Sb,Mn)(halophosphate, CHP) was used in fluorescent lamps for general lighting purposes. In this case, the UV radiation, generated by the $\mathrm{Hg}$ discharge, is absorbed by $\mathrm{Sb}^{3+}$ and partly transferred to $\mathrm{Mn}^{2+}$. The combination of a blue $\left(\mathrm{Sb}^{3+}\right)$ and yellow $\left(\mathrm{Mn}^{2+}\right)$ emission band results in white light. Nowadays, rare earth phosphors are important components of fluorescent lamps. For example, BaMgA$-\mathrm{l}_{10} \mathrm{O}_{17}$ doped with $\mathrm{Eu}^{2+}(\mathrm{BAM})$ is used as a blue emitting phosphor in high quality fluorescent lamps. The photons are absorbed and emitted by the $\mathrm{Eu}^{2+}$ ions, due to a $4 \mathrm{f} \rightarrow 5 \mathrm{~d}$ and a $5 \mathrm{~d} \rightarrow 4 \mathrm{f}$ optical transition, respectively. The red emission in these lamps is generated by $\mathrm{Y}_{2} \mathrm{O}_{3}: \mathrm{Eu}$. All green emitting $\mathrm{Tb}^{3+}$ phosphors rely on optical absorption on $\mathrm{Ce}^{3+}$ ions, followed by energy transfer to the emitting $\mathrm{Tb}^{3+}$ ions. $\mathrm{LaPO}_{4}: \mathrm{Ce}^{3+}, \mathrm{Tb}^{3+} ;(\mathrm{Ce}, \mathrm{Tb}) \mathrm{MgAl}_{11} \mathrm{O}_{9}$ and $(\mathrm{Ce}, \mathrm{Gd}, \mathrm{Tb}) \mathrm{MgB}_{5} \mathrm{O}_{10}$ are examples of green phosphors that can be used ${ }^{13}$.

\section{RECOVERY OF RARE EARTH METALS FROM SPENT FLUORESCENT LAMPS}

Recycling processes of spent fluorescent lamps commonly involve lamp crushing under water to avoid air pollution from mercury vapour. Hydrometallurgical and pyrometallurgical studies indicate that many methods could be applied to recovery of REEs from different wastes $^{\mathbf{6}, \mathbf{1 2}}$. The pyrometallurgical recovery processes for spent lamps usually consist of the following basic steps: feed preparation, blending and pelletizing, reduction, melting and casting ${ }^{6}$. Pyrometallurgy processes are using high temperatures. At such conditions rare earths can be oxidized easily, what makes the recovery complicated. Moreover, volatile organic compounds (VOCs) and/or dioxins are generated and this fact creates additional environmental problem ${ }^{\mathbf{1 2}}$. Rabah $^{\mathbf{6}}$ reported a combined pyro-hydrometallurgical method to recover pure metals from spent fluorescent lamps. Spent lamps were decapped under water containing $35 \%$ acetone to achieve safe capture of mercury vapour. Cleaned glass tubes were cut using a rotating diamond disc to a standard shorter length. Aluminium and copper-nickel alloys in the separated metallic parts were recovered using suitable flux to decrease metal losses going to slag. Pure aluminium was recovered by melting at $800^{\circ} \mathrm{C}$ under sodium chloride/carbon flux for $20 \mathrm{~min}$. Standard nickel-copper alloys with less than $0.1 \%$ tin were prepared by melting at $1250^{\circ} \mathrm{C}$ using a sodium borate/carbon flux. De-tinning of the molten nickel-copper alloy was carried out using oxygen gas. Subsequently, tin was recovered by reducing tin oxide using carbon or hydrogen gas at $650-700^{\circ} \mathrm{C}$. Different valuable chloride salts were also obtained of good quality ${ }^{6}$. However, these pyrometallurgical operations are energy consuming, some emission of dust and gases is also expected and moreover they are not versatile compared to hydrometallurgical processes. Hydrometallurgy shows benefits compared with pyrometallurgical techniques such as low cost requirements, possible recovery of leachants and decrease of air pollution ${ }^{\mathbf{1 5}}$. Hydrometallurgy processes use strong acidic or basic solutions to dissolve selectively and then precipitate metals of interest from a preprocessed powder form. The specific used process depends on the metal to be recovered and options include solvent extraction, leaching, and selective precipitation ${ }^{\mathbf{1 2}}$. Many patented processes have already been developed, mainly for treatment of spent lamps ${ }^{3,16-18}$. One of them is the recovery of rare earth metals from fluorescent lamps in a multistage process. The individual process steps are: mechanical separation of coarse components, separation of the halophosphate, 
leaching of mainly yttrium and europium oxides using inorganic or organic acids, extraction of rare earth metal ions from solutions and final treatment. The REEs can be precipitated from the solutions obtained in the various process steps either with oxalic acid as oxalates or with ammonia as basic salts. Subsequently the oxalates are heated to form oxides ${ }^{\mathbf{1 6}}$.

Acid leaching of metal ions contained in the phosphors powders of spent fluorescent lamps, is a very important chemical process in the treatment of these waste. Different conditions (leaching agent concentration, temperature, solid/liquid ratio, stirring intensity, etc.) were investigated. Nitric acid, hydrochloric acid, sulphuric acid were used in leaching of phosphors powders. The inorganic acids proved to be efficient leaching agents, extracting more than $80 \%$ rare earth metal ${ }^{10}$. For example, the leaching of phosphors powders with $\mathrm{HCl}$ followed by precipitation with ammonia/oxalic acid has been studied. The optimum leaching conditions were as follows: $\mathrm{HCl}$ concentration $4 \mathrm{M}$, solid/liquid ratio $100 \mathrm{~g} / \mathrm{l}$, stirring at $600 \mathrm{rpm}$, temperature of $60^{\circ} \mathrm{C}, 1 \mathrm{~h} .89 .9 \%$ of the total rare earth metals were leached, yttrium accounting for $96.3 \%^{3}$. For comparison, leaching of rare earths from the spent optical glass is very difficult using inorganic acids, such as: hydrochloric acid, nitric acid and sulphuric acid. However, it is possible to convert them to REEs hydroxides with sodium hydroxide under proper conditions, and the resulting hydroxides are very easily dissolved in inorganic acids ${ }^{\mathbf{1 4}}$.

After leaching waste fluorescent lamps using inorganic acids, solvent extraction is the most adequate process to provide an efficient purification. Actually, the solvent extraction plays an important role as a separation and concentration method. Many investigations have been conducted on the separation of REEs ions by solvent extraction processes ${ }^{6-38}$. The $\mathrm{pH}$, acid concentration, ionic strength and concentration of the metal ions in the aqueous phase influence the extraction efficiency and the selectivity of the process. Different compounds were utilized to earth metal ions extraction from the model leach liquor of phosphors powder. Table 4 gathers chosen extraction systems, which were investigated for separation

Table 4. Extraction systems applied for the separation of rare earth metal ions

\begin{tabular}{|c|c|c|}
\hline Metal ions & Extractants & Ref. \\
\hline $\mathrm{La}(\mathrm{III}), \mathrm{Eu}(\mathrm{III}), \mathrm{Lu}(\mathrm{III})$ & bis(4-acyl-5-hydroxypyrazoles) & [19] \\
\hline $\begin{array}{l}\mathrm{La}(\mathrm{III}), \mathrm{Gd}(\mathrm{III}), \mathrm{Y}(\mathrm{III}) \mathrm{Yb}(\mathrm{III}) \\
\mathrm{Sc}(\mathrm{III})\end{array}$ & $\begin{array}{l}\text { mixture of bis(2,4,4-trimethylpentyl)phosphinic acid and } \\
\text { sec-nonylphenoxy acetic acid }\end{array}$ & [20] \\
\hline $\mathrm{La}(\mathrm{III}), \operatorname{Pr}(\mathrm{III}), \mathrm{Nd}(\mathrm{III})$ & $\begin{array}{l}\text { di-2-ethylhexylphosphoric acid (DEHPA) and 2-ethylhexylphosphonic acid mono-2-ethylhexyl ester } \\
\text { (HEH(EHP)) }\end{array}$ & [21] \\
\hline $\begin{array}{l}\mathrm{La}(I I I), \mathrm{Ce}(\mathrm{III}), \operatorname{Pr}(\mathrm{III}), \mathrm{Nd}(\mathrm{III}) \\
\text { Sm(III), Gd(III), Dy(III), Y(III) }\end{array}$ & carboxylic acids such as cekanoic, naphthenic, neo-heptanoic and Versatic 10 in dodecane & [22] \\
\hline $\mathrm{La}(\mathrm{III}), \operatorname{Pr}(\mathrm{III}), \mathrm{Nd}(\mathrm{III})$ & 8-hydroquinoline with and without 2-ethylhexyl phosphoric acid mono-2-ethylhexyl ester & [23] \\
\hline $\operatorname{Th}(I I I)$ & $\begin{array}{l}\text { p-phosphorylated calix[4]arene, 5,11,17,23-tetra(diethoxyphosphoryl)-25,26,27,28-tetrapropyloxy- } \\
\text { calix[4]arene }\end{array}$ & [24] \\
\hline $\mathrm{La}(\mathrm{III}), \operatorname{Pr}(\mathrm{III}), \mathrm{Nd}(\mathrm{III})$ & $\begin{array}{l}\text { Cyanex } 272 \text { and its mixture with solvating, } \\
\text { cationic and anionic extractants like TBP, TOPO, DOS, Cyanex 301, Versatic-10, Alamine 308, } \\
\text { Alamine } 336\end{array}$ & [25] \\
\hline $\mathrm{La}(\mathrm{III}), \mathrm{Nd}(\mathrm{III})$ & $\begin{array}{l}\text { mixture of two neutral extractants: trioctylphosphine oxide (TOPO) and trialkylphosphine oxide } \\
\text { (TRPO) }\end{array}$ & [26] \\
\hline $\mathrm{La}(\mathrm{III}), \mathrm{Yb}(\mathrm{III})$ & di(2,4,4-trimethylpentyl)phosphinate of methyltrioctylammonium & [27] \\
\hline $\mathrm{La}(\mathrm{III}), \mathrm{Nd}(\mathrm{III}), \mathrm{Y}(\mathrm{III}), \mathrm{Ce}((\mathrm{II})$ & 18-crown-6 (18C6) & [28] \\
\hline $\mathrm{La}(\mathrm{III}), \mathrm{Y}(\mathrm{III}), \mathrm{Ce}(\mathrm{III})$ & Cyanex 272, Cyanex302 and TBP (HA) & [29] \\
\hline $\begin{array}{l}\mathrm{Tb}(\mathrm{III}), \mathrm{La}(\mathrm{III}), \mathrm{Ce}(\mathrm{III}), \mathrm{Lu}(\mathrm{III}) \\
\mathrm{Y}(\mathrm{III}), \mathrm{Er}(\mathrm{III}), \mathrm{Dy}(\mathrm{III}), \mathrm{Ho} \text { (III) }\end{array}$ & $\begin{array}{l}\text { phosphors solvent (TOPS 99), di-2-ethylhexyl phosphoric acid (D2EHPA), 2-ethylhexylphosphonic } \\
\text { acid mono-2-ethylhexyl ester (PC-88A), bis(2,4,4-trimethylpentyl) phosphinic acid (Cyanex 272) }\end{array}$ & [30] \\
\hline $\begin{array}{l}14 \text { lanthanoids (except Pm(III)) } \\
\text { and Y(III) }\end{array}$ & $\begin{array}{l}\text { 1-phenyl-3-methyl-4-benzoylpyrazalone-5 (HPMBP, HA), sec-octylphenoxyacetic acid (CA12, } \\
\text { H2B2) }\end{array}$ & [31] \\
\hline $\begin{array}{l}\mathrm{La}(\mathrm{III}), \mathrm{Ce}(\mathrm{III}), \mathrm{Nd}(\mathrm{III}), \mathrm{Y}(\mathrm{III}) \\
\mathrm{Eu}(\mathrm{III})\end{array}$ & $\begin{array}{l}\text { binary extractants, such as salts of trioctylmethylammonium with dialkylphosphinic, } \\
\text { dialkylmonothiophosphinic, dialkyldithiophosphinic acids }\end{array}$ & [32] \\
\hline $\mathrm{La}(\mathrm{III}), \mathrm{Gd}(\mathrm{III})$ & Aliquat-336, Amberlite XAD-4 & [33] \\
\hline $\mathrm{La}(\mathrm{III}), \mathrm{Sm}(\mathrm{III}), \mathrm{Er}(\mathrm{III})$ & 2-ethylhexylphosphonic acid mono-2-ethylhexyl ester (EHPNA) & [34] \\
\hline $\mathrm{La}(\mathrm{III}), \mathrm{Nd}(\mathrm{III})$ & 2-ethylhexylphosphonic acid mono-2-ethylhexyl ester (PC88A) & [35] \\
\hline $\mathrm{La}(\mathrm{III}), \operatorname{Th}(\mathrm{III}), \mathrm{Eu}(\mathrm{III})$ & bis(2-ethylhexyl)phosphoric acid using 2-nitrobenzo-18-crown-6 & [36] \\
\hline $\mathrm{La}(\mathrm{III})$ & $\begin{array}{l}\text { 1-phenyl-3-methyl-4-benzoyl-pyrazalone-5 (HPMBP) and triisobutylphosphine sulphide } \\
\text { (TIBPS) }\end{array}$ & [37] \\
\hline
\end{tabular}


of rare earths metal ions ${ }^{19-37}$. Recently, recovery and separation of rare earths metal ions from aqueous solutions was examined using different extractants, i.e. solvating type extractants ${ }^{6,7,26,27,30}$, amine extractants ${ }^{28,29,31,32}$, acidic extractants (carboxylic and organophosphorous acids $)^{21-25,33-36}$. Extractants applied for separation and recovery of REEs from aqueous solutions should be efficient and selective. These properties are one of the most important criterion during development of metals recovery technologies. Up to date, some papers show solvent extraction of REEs using ionic liquids or their mixture in a role of new and efficient extractants. Investigation of metallurgical and hydrometallurgical research indicates that many techniques can be used to improve the recycling processes of spent fluorescent lamps. Rabah et al. ${ }^{6,7}$ reported a combined pyro-hydrometallurgical method recovery of aluminum, nickel-copper alloys, europium and yttrium metals and various salts from spent fluorescent lamps. The rare earth metals and some valuable salts were recovered from the powder coating the inner surface of the glass tubes. The tubes were broken under $30 \%$ aqueous acetone to avoid emission of mercury vapor to the atmosphere, and the powder was collected by brushing. The powder contained $1.62 \%$ europium oxide, $1.65 \%$ yttrium oxide, $34.48 \%$ calcium sulphate, $61.52 \% \mathrm{Ca}$ orthophosphate and $0.65 \%$ other metal oxides by weight. Metals present in the powder were pressure leached using $\mathrm{H}_{2} \mathrm{SO}_{4} / \mathrm{HNO}_{3}$ mixture.

$\mathrm{Eu}_{2} \mathrm{O}_{3}+3 \mathrm{H}_{2} \mathrm{SO}_{4} \rightarrow 2 \mathrm{Eu}\left(\mathrm{SO}_{4}\right)_{3}+3 \mathrm{H}_{2} \mathrm{O}$

$\mathrm{Y}_{2} \mathrm{O}_{3}+3 \mathrm{H}_{2} \mathrm{SO}_{4} \rightarrow 2 \mathrm{Yu}\left(\mathrm{SO}_{4}\right)_{3}+3 \mathrm{H}_{2} \mathrm{O}$

$\mathrm{Ca}_{3}\left(\mathrm{PO}_{4}\right)_{2}+3 \mathrm{H}_{2} \mathrm{SO}_{4} \rightarrow 3 \mathrm{CaSO}_{4}+2 \mathrm{H}_{3} \mathrm{PO}_{4}$

The autoclave digestion of the powder in the acid mixture for $4 \mathrm{~h}$ at $125^{\circ} \mathrm{C}$ and $5 \mathrm{MPa}$ resulted in dissolving $96.4 \%$ of the yttrium and $92.8 \%$ of the europium. The obtained mixture of sulphate salts of europium and yttrium was subsequently converted to thiocyanate at low temperature. Extraction of $\mathrm{Eu}(\mathrm{III})$ and $\mathrm{Y}(\mathrm{III})$ ions from the thiocyanate solution attained its maximum at $80^{\circ} \mathrm{C}$ using tri- $n$-butyl phosphate (TBP) in $1 \mathrm{M} \mathrm{HNO}_{3}$. Thermal reduction using hydrogen gas at $850^{\circ} \mathrm{C}$ and $1575^{\circ} \mathrm{C}$ produced europium and yttrium metals, respectively.

$\mathrm{M}\left(\mathrm{NO}_{3}\right)_{3}+3 \mathrm{H}_{2} \rightarrow \mathrm{M}+3 \mathrm{NO}_{2}+3 \mathrm{H}_{2} \mathrm{O}$

TBP is one of the most known and widely applied extractants in separation process of REEs. This is kind of neutral extractant which was used also in the separation of actinides. TBP can be also used as modifier of solvent extraction which reduce the possibility of third phase formation.

Hirajima et al. ${ }^{8,9}$ showed the separation of low-density calcium halo-phosphate phosphors from high density rare earth-activated phosphors through dense-medium centrifugation. A sink product assaying $48.6 \%$ of rare earth-activated phosphors could be recovered from waste phosphor materials pre-treated with $5 \cdot 10^{-5} \mathrm{~mol} / \mathrm{dm}^{3}$ of sodium oleate $(\mathrm{NaOl})$ surfactant. For example, the yield, grade and recovery of rare earth-activated phosphors in the sink product were $21.3,38.7$ and $97.3 \%$, respectively.

Michelis et al. ${ }^{10}$ described recovery of yttrium from fluorescent lamp powder from dismantling of spent fluorescent tubes. Metals were leached by using different acids $\left(\mathrm{HNO}_{3}, \mathrm{HCl}, \mathrm{H}_{2} \mathrm{SO}_{4}\right)$ and ammonia solutions. The investigations showed that ammonia solutions was not suitable to recover yttrium, whereas $\mathrm{HNO}_{3}$ produces toxic vapours. On the other hand, $\mathrm{HCl}$ and $\mathrm{H}_{2} \mathrm{SO}_{4}$ were suitable as solvents. The highest extraction of yttrium was obtained by $20 \% \mathrm{w} / \mathrm{v} \mathrm{S} / \mathrm{L}$ ratio, $4 \mathrm{~N} \mathrm{H}_{2} \mathrm{SO}_{4}$ concentration at $90^{\circ} \mathrm{C}$. Yttrium and calcium yields were nearly 85 and 5\%, respectively. Yttrium can be subsequently recovered from liquor leach by precipitation as a pure yttrium oxalate $n$-hydrate (99\% grade) by using the stoichiometric amount of oxalic acid. A block diagram of this process for the recovery of yttrium from spent fluorescent lamps is shown in Figure 1.

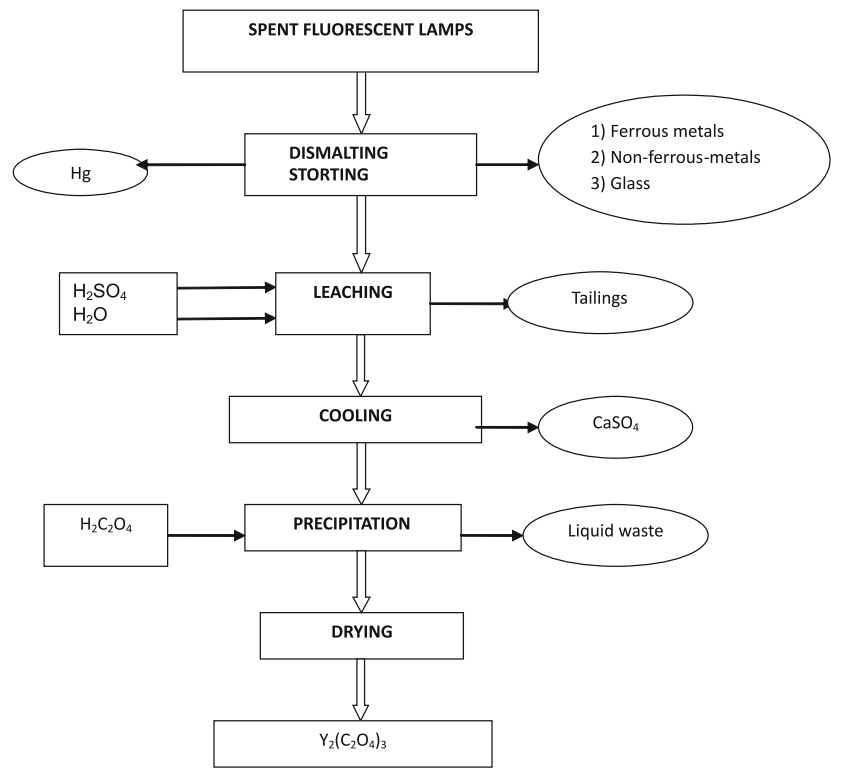

Figure 1. Flow sheet of the process for the recovery of yttrium from spent fluorescent lamps (adapted from ${ }^{10}$ )

Shimizu et al. ${ }^{17}$ reported the extraction of rare earth elements from luminescent material from waste fluorescent lamps using supercritical carbon dioxide $\left(\mathrm{SF}-\mathrm{CO}_{2}\right)$ containing tri- $n$-butyl phosphate (TBP) complexes with $\mathrm{HNO}_{3}$ and $\mathrm{H}_{2} \mathrm{O}$. The content of the major elements in the luminescent material was a follows: $29.6 \%$ of $\mathrm{Y}$, $10.6 \%$ of $\mathrm{La}, 5.0 \%$ of $\mathrm{Ce}, 2.6 \%$ of $\mathrm{Tb}, 2.3 \%$ of $\mathrm{Eu}$. Y and $\mathrm{Eu}$ were present as oxides, whereas $\mathrm{La}$ and $\mathrm{Ce}$ were present as phosphates. It was not possible to identify the structure of $\mathrm{Tb}$. Yttrium and Eu were directly extracted from luminescent material using extraction by $\mathrm{SF}-\mathrm{CO}_{2}$ containing tri- $n$-butyl phosphate (TBP) complexes with $\mathrm{HNO}_{3}$ and $\mathrm{H}_{2} \mathrm{O}$ for 120 min. at $15 \mathrm{MPa}, 333 \mathrm{~K}$. The extraction efficiencies of $\mathrm{Y}$ and Eu were $99.7 \%$ and $99.8 \%$, respectively. The dissolution and extraction reactions of lanthanide oxides can be showed by the following equations:

$\mathrm{Ln}_{2} \mathrm{O}_{3}+6 \mathrm{HNO}_{3} \rightarrow 2 \mathrm{Ln}^{3+}+6 \mathrm{NO}_{3}^{-}+3 \mathrm{H}_{2} \mathrm{O}$

$\mathrm{Ln}^{3+} 3 \mathrm{NO}_{3}^{-}+\mathrm{nTBP} \rightarrow \mathrm{Ln}\left(\mathrm{NO}_{3}\right)_{3}(\mathrm{TBP})_{\mathrm{n}}$

Naitou et al. ${ }^{18}$ studied recovery of rare earth oxides from a waste rare earth phosphors. This process consisted of a strong $\mathrm{HCl}$ leaching at $70^{\circ} \mathrm{C}$ with hydrogen peroxide (or leaching with only $\mathrm{HNO}_{3}$ only), followed by precipitation of rare earths by oxalic acid addition.

Several studies have reported the characterization and recovery process of the phosphor powders from the spent fluorescent lamps ${ }^{5,19}$. The analytical results presented by Raposo at al. ${ }^{5}$ showed that the phosphors powder matrix 
is a hazardous and polluting material in the waste of spent fluorescent lamps. Mercury concentrations in this type of matrix are much higher than that in new lamps of the same kind, in some cases even 40-fold. The basic difference is that mercury in spent lamps is adsorbed primarily into the phosphors matrix and, to a lesser extent, into glass and other components. In new lamps, mercury predominates as a vapor phase element.

Chang et al. ${ }^{13}$ described the physical characteristic, crystal structure and the luminescence properties of the phosphor powders recovered from the spent fluorescent lamps. The experimental results showed that the halophosphate contains small amount of rare-earth elements including $\mathrm{La}, \mathrm{Gd}, \mathrm{Tb}$ and $\mathrm{Eu}$, due to the contamination from other phosphors during the recycling process. After the thermal desorption/distillation process at temperatures between 300 and $800^{\circ} \mathrm{C}$, mercury was effectively removed from the phosphor powder. The composition of the phosphors powders before and after the thermal treatment are showed in Table 2. The recovered phosphor can be mixed with the fresh phosphor and used in the fluorescent lamps again ${ }^{13}$. Innocezi et al. ${ }^{38}$ showed results of yttrium recovery from fluorescent powder of lamps and cathode ray tubes (CRTs). The process for treating these materials includes the following steps: (1) acid leaching, (2) purification of the leach liquors using sodium hydroxide and sodium sulfide, (3) precipitation of yttrium using oxalic acid, and (4) calcinations of oxalates for production of yttrium oxides. The recoveries of yttrium oxide are about 95,55 , and $65 \%$ for CRT, lamps, and CRT/lamp mixture powders, respectively. The lower yields obtained during treatments of lamp powders are probably due to the co-precipitation of yttrium together with other metals contained in the lamps powder. The possibility to treat simultaneously both CRT and lamp powders is very important and interesting from an industrial point of view since it could be possible to run a single plant treating fluorescent powder coming from two different electronic wastes ${ }^{38}$.

\section{CONCLUSIONS}

Safe disposal of spent fluorescent lamps becomes a serious problem due to the presence of toxic mercury and therefore the development of their effective recycling process is very important. What is even more important, some economic benefits can be achieved in recovery of value earth metals with important possible applications in numerous fields. Various techniques utilized in recovery of rare earth metals such as: yttrium, terbium, europium, lanthanum, and other REEs from spent fluorescent lamps have been reviewed. The hydrometallurgical technologies are the main methods which are used to recycle or dispose of the spent lamps. The metals from these wastes can be recovered by leaching using inorganic acids. The recovered metal ions are separated by solvent extraction and subsequently are precipitated as salts. Pyrometallurgy processes are the energy consuming technologies. Moreover during smelting, volatile organic compounds (VOCs) and dioxins could be generated. Review demonstrated that the fundamental processes used for recycling of REEs are identical or very similar to those utilized for the raw ores processing.

\section{ACKNOWLEMENT}

This work was partially financed by inLab Project (Toruń, Poland). Authors are grateful to Ms. Edyta Rynkowska for her engagement in the literature survey. Special thanks are due to M.Sc. Karolina Jarzynka for her kind assistance with the text editing.

\section{LITERATURE CITED}

1. Durao, W., Castro, C. \& Windmöller, C. (2008). Mercury reduction studies to facilitate the thermal decontamination of phosphor powder residues from spent fluorescent lamps. Waste Management 28, 2311-2319. DOI: 10.1016/j.wasman.2007.10.011.

2. Chang, T., You, S., Yu, B. \& Kong, H. (2007). The fate and management of high mercury-containing lamps from high technology industry. J. Hazard. Mater. 141, 784-792. DOI: 10.1016/j.hazmat.2006.07.045.

3. Tunsu, C., Retegan, T. \& Ekberg, Ch. Sustainable processes development for recycling of fluorescent phosphorous powders - rare earth and mercury separation, Literature report, Chalmers University and Technology, Gothenburg, Sweden, 2012, http://publications.lib.chalmers.se/records/fulltext/local_157270. pdf (24.01.2013).

4. Rey-Raap, N. \& Gallardo, A. (2012). Determination of mercury distribution inside spent compact fluorescent lamps by atomic absorption spectrometry. Waste Management 32, 944-948. DOI: 10.1016/j.wasman.2011.12.001.

5. Raposo, C., Windmölle, C. \& Junior, W. (2003). Mercury speciation in fluorescent lamps by thermal release analysis. Waste Management 23, 879-886. DOI: 10.1016/SO956-053X(03)00089-8.

6. Rabah, M.A. (2004). Recovery of aluminum, nickel-copper alloys and salts from spent fluorescent lamps. Waste Management 24, 119-126. DOI:10.1016/j.wasman.2003.07.001.

7. Rabah, M.A. (2008). Recyclables recovery of europium and yttrium metals and some salts from spent fluorescent lamps. Waste Management 28, 318-325. DOI: 10.1016/j.wasman.2007.02.006.

8. Hirajima, T., Sasaki, K., Bissombolo, A., Hirai, H., Hamada, M., Tsunekawa, M. (2005). Feasibility of an efficient recovery of rare earth-activated phosphors from waste fluorescent lamps through dense-medium centrifugation. Sep. Purif. Technol. 44, 197-204. DOI:10.1016/j.seppur.2004.12.014.

9. Hirajima, T., Bissombolo, A., Sasaki, K., Nakayama, K., Hirai, H. \& Tsunekawa, M. (2005). Feasibility of a of rare earth phosphors from waste fluorescent lamps. Int. J. Miner. Process. 77, 187-198. DOI:10.1016/j.minpro.2005.05.002.

10. Michelis, I., Ferella, F., Varelli, E.F. \& Veglio, F. (2011). Treatment of exhaust fluorescent lamps to recover yttrium: Experimental and process analyses, Waste Management 31, 2559-2568. DOI:10.1016/j.wasman.2011.07.004.

11. Ronda, C.R., Jüstel, T. \& Nikol, H. (1998). Rare earth phosphors: fundamentals and applications. J. Alloys Comp.275277, 669-676. PII: S0925-8388(98)00416-2.

12. Rare Earth Elements - EPA/600/R-12/572 Report. 2012. [cited on 2014, Jan 9]. Available from http://nepis.epa.gov/ Adobe/PDF/P100EUBC.pdf.

13. Chang, T.Ch., Wang, S.F., You, S.J. \& Cheng, A. (2007). Characterization of halophsosphate phosphor powders recovered from the spent fluorescent lamps. J. Environ. Eng. Manage. 17(6), 435-439.

14. Jiang, Y., Shibayama, A., Liu, K. \& Fujita, T. (2005). A hydrometallurgical process for extraction of lanthanum, yttrium and gadolinium from spent optical glass. Hydrometallurgy 76, 1-9. DOI: 10.1016/j.hydromet.2004.06.010.

15. Sayilgan, E., Kukrer, T., Civelekoglu, G., Ferella, F., Akcil, A., Veglio, F. \& Kitis, M. (2009). A review of technologies for the recovery of metals from spent alkaline and zinc- 
carbon batteries. Hydrometallurgy 97, 158-166. DOI:10.1016/j. hydromet.2009.02.008.

16. Otto, R. \& Wojtalewicz-Kasprzak, A. (2012). Patent No. 20120027651. Chemistry of inorganic compounds treating mixture to obtain metal containing compound rare earth metal.

17. Shimizu, R., Sawada, K., Enokida, Y. \& Yamamoto, I. (2005). Supercritical fluid extraction of rare earth elements from luminescent material in waste fluorescent lamps. J. Supercrit. Fluids 33, 235-241. DOI:10.1016/j.supflu.2004.08.004.

18. Naitou, M., Yoshikawa, M. \& Narita, K. (1987). U.S. Patent No. 4650652. Process for recovering highly pure rare earth oxides from a waste rare earth phosphor.

19. Bou-Maroun, E., Chebib, H., Leroy, M.J.F. \& Boos, A. (2006). Solvent extraction of lanthanum(III), europium(III) and lutetium(III) by bis(4-acyl-5-hydroxypyrazoles) derivatives. Sep. Purif. Technol. 50, 220-228. DOI: 10.1016/j.seppur.2005.11.029.

20. Sun, X., Wang, J., Li, D. \& Li, H. (2006). Synergistic extraction of rare earths by mixture of bis(2,4,4-trimethylpentyl) phosphinic acid and Sec-nonylphenoxy acetic acid. Sep. Purif. Technol. 50, 30-34. DOI: 10.1016/j.seppur.2005.11.004.

21. Morais, C.A. \& Ciminelli, V.S.T. (2004). Process development for the recovery of high-grade lanthanum by solvent extraction. Hydrometallurgy 73, 237-244. DOI: 10.1016/j. hydromet.2003.10.008.

22. Singh, D.K., Singh, H. \& Mathur, J.N. (2006). Extraction of rare earths and yttrium with high molecular weight carboxylic acids. Hydrometallurgy 81, 184-181. DOI:10.1016/j. hydromet.2005.12.002.

23. Wu, D., Zhang, Q. \& Bao, B. (2007). Solvent extraction of $\mathrm{Pr}$ and $\mathrm{Nd}$ from chloride-acetate medium by 8 -hydroquinoline with and without 2-ethylhexyl phosphoric acid mono-2-ethylhexyl ester as an added synergist in heptane diluent. Hydrometallurgy 88, 210-215. DOI: 10.1016/j.hydromet.2007.05.009.

24. Lu, Y., Bi, Y., Bai, Y. \& Liao, W. (2013). Extraction and separation of thorium and rare earths from nitrate medium with $p$-phosphorylated calixarene. J. Chem. Technol. Biotechnol. http://onlinelibrary.wiley.com (15.03.2013) DOI :10.1002/ jctb.4035/pdf.

25. Banda, R., Jeon, H., Lee, M. (2012). Solvent extraction separation of Pr and Nd from chloride solution containing La using Cyanex 272 and its mixture with other extractants. Sep. Purif. Technol. 98, 481-489. DOI:10.1016/j.seppur.2012.08.015.

26. El-Nadi, Y.A. (2012). Lanthanum and neodymium from Egyptian monazite: Synergistic extractive separation using organophosphors reagents. Hydrometallurgy 119-120, 23-29. DOI: 10.1016/j.hydromet.2012.03.003.

27. Belova, V., Voshkin, A., Egorova, N. \& Kholkin, A. (2012). Solvent extraction of rare earth metals from nitrate solutions with di(2,4,4-trimethylpentyl)phosphinate of methyltrioctylammonium. J. Molec. Liquids 172, 144-148. DOI: 10.1016/j.molliq.2012.04.012.

28. El-Hefny, N.E., El-Nadi, Y.A. \& Ahmed, I.M. (2011). 18-Crown-6 for the selective extraction and separation of cerium(IV) from nitrate medium containing some lanthanides. Inter. J. Miner. Proces. 101, 58-62. DOI: 10.1016/j. minpro.2011.07.013.

29. Eskandari Nasab, M.E., Sam, A. \& Milani, S.A. (2011). Determination of optimum process conditions for the separation of thorium and rare earth elements by solvent extraction. $\mathrm{Hy}$ drometallurgy 106, 141-147. DOI:10.1016/j.hydromet.2010.12.014

30. Radhika, S., Nagaphani Kumar, B., Lakshmi Kantam, M. \& Ramachandra Reddy, B. (2010). Liquid-liquid extraction and separation possibilities of heavy and Ligot rare-earths from phosphoric acid solutions with acidic organophosphors reagents. Sep. Purif. Technol. 75, 295-302. DOI: 10.1016/j. seppur.2010.08.018.

31. Tong, S., Song, N., Jia, Q., Zhou, W. \& Liao, W. (2009).

Solvent extraction of rare earths from chloride medium with mixtures of 1-phenyl-3-methyl-4-benzoyl-pyrazalone-5 and sec- octylphenoxyacetic acid. Sep. Purif. Technol. 69, 97-101. DOI: 10.1016/j.seppur.2009.07.003.

32. Belova, V.V., Voshkin, A.A., Kholkin, A.I. \& Payrtman, A.K. (2009). Solvent extraction of some lanthanides from chloride and nitrate solutions by binary extractants, Hydrometallurgy 97, 198-203. DOI:10.1016/j.hydromet.2009.03.004.

33. El-Sofany, E.A. (2008). Removal of lanthanum and gadolinium from nitrate medium using Aliquat-336 impregnated onto Amberlite XAD-4. J. Hazard. Mater. 153, 948-954. DOI:10.1016/j.jhazmat.2007.09.046.

34. Kamio, E., Fujiwara, Y., Matsumoto, M., Valenzuela, F. \& Kondo, K. (2008). Investigation on extraction rate of lanthanides with extractant-impregnated microcapsule. Chem. Engine. J. 139, 93-105. DOI: 10.1016/j.cej.2007.07.072.

35. Kao, H.Ch., Yuang, P. \& Juang, R. (2006). Solvent extraction of $\mathrm{La}(\mathrm{III})$ and $\mathrm{Nd}(\mathrm{III})$ from nitrate solutions with 2-ethylhexylphosphonic acid mono-2-ethylhexyl ester. Chem. Engine. J. 119, 167-174. DOI: 10.1016/j.cej.2006.03.024.

36. Zamani, A.A. \& Yaftian, M.R. (2004). Solvent extraction of thorium, lanthanum and europium ions by bis(2-ethylhexyl) phosphoric acid using 2-nitrobenzo-18-crown-6 as ion size selective masking agent. Sep. Purif. Technol. 40, 115-121. DOI: 10.1016/j.seppur.2004.01.012.

37. Jia, Q, Liao, W., Li, D. \& Niu, Ch. (2003). Synergistic extraction of lanthanum(III) from chloride medium bymixtures of 1-phenyl-3-methyl-4-benzoyl-pyrazalone-5 and triisobutylphosphine sulphide. Analyt. Chimi. Acta 477, 251-256. PII: S0003-2670(02)01430-7.

38. Innocezi, V., De Michaelis, I., Ferella, F. \& Veglio, F. (2013). Recovery of yttrium from cathode ray tubes and lamps' fluorescent powders: experimental results and economic simulation. Waste Manag. 33(11), 2390-2396. DOI: 10.1016/j. wasman.2013.06.002. 